\title{
PRODUCCIÓN DE HÍBRIDOS INTERESPECÍFICOS ENTRE Nierembergia ericoides Y Nierembergia linariaefolia MEDIANTE LA APLICACIÓN DE TÉCNICAS DE RESCATE EMBRIONARIO
}

\author{
PRODUCTION OF interspecific HYBRIDS BETWEEN Nierembergia ericoides \\ AND Nierembergia linariaefolia THROUGH THE APPLICATION OF EMBRYO \\ RESCUE TECHNIQUES \\ Víctor José Milicia $^{1 *}$, Ángel Chiesa ${ }^{1}$, Andrea Coviella ${ }^{2}$ y María Silvina Soto ${ }^{2}$ \\ ${ }^{1}$ Facultad de Ciencias Agrarias, Universidad Nacional de Lomas de Zamora, Ruta Provincial № 4 y \\ Juan XXIII, Lomas de Zamora, Argentina. \\ 2 Instituto de Floricultura, Instituto Nacional de Tecnología Agropecuaria, Nicolas Repetto y de los \\ Reseros s/n (1686), Hurlingham, Argentina. \\ * Autor para correspondencia E-mail: victormilicia@hotmail.com
}

\section{RESUMEN}

La hibridación interespecífica es una de las técnicas más utilizadas en el mejoramiento de plantas ornamentales, debido a su alto potencial para obtener vigor híbrido y variación en caracteres, aspectos que no se expresan en las especies originales. El objetivo del presente estudio es obtener híbridos interespecíficos de Nierembergia ericoides Miers $\times N$. linariaefolia Graham utilizando el rescate embrionario, a través del cultivo de óvulos como herramienta para sortear las barreras post-cigóticas. Los óvulos fueron aislados 7 días luego del cruzamiento-polinización y cultivados en medio Murashige y Skoog (MS) modificado. Se realizaron tres fechas de siembra: A: 3/10/17; B: 3/11/17; C: 13/12/17. Los óvulos cuyos embriones iniciaron su desarrollo emitiendo la radícula, se repicaron a tubos de ensayo con medio de cultivo MS modificado. Los tubos se colocaron en cámara de cultivo a $25^{\circ} \mathrm{C}$ con fotoperíodo de 12 horas e intensidad de 4000 lux. Se comparó el número de óvulos germinados respecto al total sembrados y la cantidad de plántulas obtenidas respecto de los óvulos germinados. Se obtuvieron cinco plántulas de 931 óvulos sembrados en la primera fecha, mientras que en la segunda, se obtuvieron cinco de 642 óvulos sembrados. En la tercera fecha, hubo contaminación fúngica, lo que impidió registrar datos. Se puede concluir que la técnica de rescate embrionario a partir del cultivo de óvulos de Nierembergia permitió obtener exitosamente cruzamientos efectivos entre especies incompatibles.

Palabras clave: barreras post-cigóticas, plantas ornamentales, mejoramiento, cultivo in vitro, plantas nativas.

\section{ABSTRACT}

Interspecific hybridization is one of the most widely used techniques in the improvement of ornamental plants because of its high potential to obtain hybrid vigor and character variation, which are not expressed in the original species. The aim of this study was to obtain interspecific hybrids of Nierembergia ericoides Miers $\times N$. linariaefolia Graham using the embryo rescue technique through ovule culture as a tool to overcome post-zygotic barriers. The ovules were isolated 7 days after crosspollination and cultured in modified Murashige and Skoog (MS) medium. Three sowing dates were carried out: A: 3/10/17; B: 3/11/17; C: 13/12/17. The ovules, whose embryos began their development

Recibido: 11 julio 2018. Aceptado: 24 septiembre 2018. 
(those with the radicle emerged), were placed into test tubes with modified MS culture medium. The tubes were placed in a culture chamber at $25^{\circ} \mathrm{C}$ with a photoperiod of 12 hours and a light intensity of 4000 lux. The number of germinated ovules was compared to the total number of cultured ovules, while the number of seedlings obtained was compared to the number of germinated ovules. Five seedlings were obtained from 931 ovules cultured on the first date, and the same number was obtained from 642 ovules cultured on the second date. A fungal contamination occurred on the third culture date, which prevented data collection. It can be concluded that embryo rescue by the culture of Nierembergia ovules successfully allowed obtaining effective crosses between incompatible species.

Key words: Post-zigotic barriers, ornamental plants, breeding, in vitro cultivation, native plants.

\section{INTRODUCCION}

El género Nierembergia, junto a Calibrachoa, Glandularia y Mercadonia, son los géneros más importantes dentro de los planes de mejoramiento de plantas herbáceas ornamentales para maceta llevados adelante por el Instituto Nacional de Tecnología Agropecuaria (INTA). Se cuenta hasta el momento con más de 15 variedades registradas, muchas de las cuales se encuentran actualmente en el mercado nacional e internacional.

El género Nierembergia (Solanaceae) comprende alrededor de 20 especies, todas ellas nativas de Sudamérica, excepto una de origen mexicano (Vignoli-Silva y Mentz, 2006). El centro de distribución está en Argentina, con 15 especies, muchas de las cuales tienen valor ornamental debido al color y vistosidad de sus flores, junto al largo período de floración, entre otras características (Soto y Coviella, 2013).

En 1999 el Instituto de Floricultura del INTA comienza un plan de mejoramiento con fines ornamentales en el género Nierembergia, habiendo obtenido hasta el momento cinco variedades registradas. Durante la primera etapa de mejoramiento se trabajó con la variabilidad intraespecífica presente en $N$. linariaefolia, habiendo obtenido tres variedades comerciales ('Estrella INTA-JICA', 'Luna INTA JICA' y 'Cielo INTA'). Posteriormente, la búsqueda de mayor variabilidad llevó a la incorporación de la hibridación interespecífica como herramienta del mejoramiento, logrando con éxito la hibridación entre $N$. scoparia y N. ericoide, habiendo obtenido variedades ornamentales como 'Yvoti blanca INTA' (Resolución 477-E/2017). La búsqueda de nuevas combinaciones para la obtención de nuevos híbridos impulsó nuevos trabajos de investigación vinculados a la identificación de barreras de incompatibilidad y posibles técnicas para poder superarlas, siendo los cruzamientos de $N$. ericoide y $N$. scoparia con $N$. linariaefolia las combinaciones más promisorias para futuros productos florícolas (Milicia, 2015).

La hibridación interespecífica es considerada como uno de los recursos más importantes en el mejoramiento de plantas ornamentales, por presentar alta potencialidad para obtener vigor híbrido, así como también la posibilidad de combinar pooles génicos dando variación en caracteres que en las especies originales no se expresan (Kato, 2012). Esta técnica tiene un enorme potencial para aprovechar la herencia transgresiva en los caracteres cuantitativos y cualitativos, así como también los genes con dominancia vinculados a comportamientos del medio ambiente o relacionados con diferente tolerancia tanto a estrés bióticos como abióticos (Horn, 2002; Van Tuyl and De Jeu, 2005). En efecto, los cruzamientos interespecíficos fueron herramientas básicas en programas de mejoramiento de cultivos. El género Lilium constituye uno de los ejemplos de mayor importancia dentro de los cultivos ornamentales contribuyendo a la obtención de cruzamientos entre los Lilium longiflorum Thunb. y los Lilium asiáticos (Rhee, 2008). Géneros como Petunia, Bougainvillea, Lilium, Amaryllis, Hemerocallis, entre otros, constituyen claros ejemplos de hibridación interespecífica aplicada en floricultura (De, 2017).

Si bien la hibridación se presenta como una técnica de gran aplicación, la obtención de híbridos interespecíficos está muchas veces limitada por diferentes barreras de incompatibilidad (Kuligowska et al., 2015). Las barreras que limitan los métodos sexuales de reproducción en algunos casos han sido identificadas primero y sorteadas después produciendo variaciones genéticas y eventualmente germoplasma mejorado (Yermishin et al., 2017).

Entre las técnicas para intentar superar las barreras postcigóticas, el rescate embrionario es una de las más utilizadas, donde la identificación de los factores involucrados también resulta de suma importancia, siendo identificados, entre ellos, la presencia de genes letales, la desarmonía genética en el embrión o fracaso en el desarrollo del endosperma en etapas tempranas (Shivanna, 2005). En Solanaceae se han identificado barreras que incluyen esterilidad masculina núcleocitoplasmática (Pino Pèrez, 2012), poliploidía (Thompson y Lumaret, 1992), interacción estilo-tubo polínico (Kuligowska et al., 2015) e interrupción del desarrollo del endosperma (Birchler, 2014). 
El rescate embrionario, como metodología para la obtención de híbridos, ha sido utilizado exitosamente en muchos cultivos, siendo Lilium el género modelo en las técnicas de manipulación de estilo y de cultivo in vitro (Van Tuyl y De Jeu, 2005). Otros ejemplos en los cuales se haya empleado el rescate embrionario para la obtención de híbridos interespecíficos con fines ornamentales, se encuentran en los géneros Begonia (Chen, 2012), Dendranthema (Xi Cheng, 2010), Alstroemeria L., (Van Tuyl y De Jeu, 2005). Dentro de la familia Solanaceae estas técnicas han sido utilizadas con éxito en géneros como Capsicum (Debbarama, 2013), Nicotiana (Liao, 2017), Solanum (Gaiero, 2017). El rescate embrionario presenta dos puntos a tener en cuenta, el primero es el aislamiento del embrión, y aquí se debe considerar el estado del mismo, y la metodología utilizada. El segundo punto es el medio óptimo en el cual debe desarrollase el embrión para asegurar el crecimiento y la diferenciación (Van Tuyl y De Jeu, 2005).

Teniendo en cuenta que estudios de embriología en el género Nierembergia revelaron que cruzamientos interespecíficos entre $N$. scoparia y $N$. ericoides con $N$. linariaefolia, actuando esta última como parental masculino, parecen ser las combinaciones putativas para la obtención de híbridos (Soto, 2007). El presente trabajo tiene como objetivo la obtención de híbridos entre $N$. ericoide $\times N$. linariaefolia utilizando el rescate embrionario como herramienta para sortear las barreras post-cigóticas. Por otro lado, se evalúan tres fechas diferentes de cosecha de embriones durante el período reproductivo de la especie para identificar el mes óptimo para realizar los cruzamientos y posteriores rescates. Si bien la época de floración de la especie es primavera estival por ser una especie de fotoperíodo largo, en cruzamientos intra-específicos se utiliza la primavera como etapa reproductiva debido al mejor estado fitosanitario de los materiales vegetales, encontrando una disminución del vigor de la planta a lo largo del verano. Esto se debe a un agotamiento por un exceso de floración de los genotipos superiores que son los elegidos como parentales para el mejoramiento.

\section{MATERIALES Y MÉTODOS}

Se realizaron cruzamientos interespecíficos entre N. ericoides Miers y N. lineariaefolia Graham utilizando tres variedades comerciales de esta última: $N$. ericoides $\times$ Estrella INTA-JICA; $N$. ericoides $\times$ Luna INTA-JICA; N. ericoides $\times$ Cielo INTA, tomando como control el cruzamiento $N$. ericoides $\times N$. scoparia Sendth por ser una combinación compatible (Soto, 2007). Fueron realizados 10 cruzamientos por cada combinación en tres fechas diferentes A: 26/09/17; B: 27/10/17; C: 06/12/17.

Los cruzamientos se realizaron en los invernaderos del Instituto de Floricultura del Instituto Nacional de Tecnología Agropecuaria

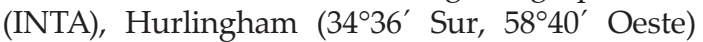
durante la primavera-verano del año 2017.

A efectos de dirigir la polinización se tomaron las flores de $N$. ericoides en estado temprano de pimpollo con una longitud entre uno y dos centímetros. A estos pimpollos se les retiró la porción superior de los pétalos y los estambres, dejando libre el estigma, el cual fue polinizado con polen fresco de la especie putativa paterna.

Pasados siete días post polinización (DPP) se cosecharon los ovarios y se desinfectaron por inmersión durante 10 minutos en alcohol etílico al $70 \%$. En condiciones de asepsia dadas por el uso de un flujo laminar, se dejaron secar sobre una placa de Petri estéril. Tomando cada uno de los ovarios se los seccionó por los nervios dorsales longitudinales para poder extraer los óvulos junto con la placenta con un bisturí y sembrarlos en número de 10 cruzamientos por placa de Petri de nueve centímetros con $25 \mathrm{~mL}$ de medio de cultivo esterilizado en autoclave en condiciones estándar. Se realizaron tres siembras en diferentes momentos del año: A: 3/10/17; B: 3/11/17; C: 13/12/17. Se utilizó medio de cultivo Murashige y Skoog (MS) modificado, macro elementos al $50 \%$, sacarosa $40 \mathrm{~g} \mathrm{~L}^{-1} \mathrm{y}$ la adición de glutamina a razón de $146 \mathrm{mg} \mathrm{L}^{-1}$. La glutamina debido a su naturaleza termolábil se esterilizó por filtrado y se incorporó al medio licuado, inmediatamente antes de su distribución. Las cajas se colocaron en cámara de cultivo a $25 \pm 2^{\circ} \mathrm{C}$ con nictoperíodo de 24 horas.

Se relevó la germinación de los óvulos, considerando como germinación a la emisión de la radícula. Los óvulos cuyos embriones iniciaron su desarrollo emitiendo la radícula, se repicaron a tubos de ensayo con medio de cultivo MS modificado de la siguiente forma: macroelementos al $50 \%$ con $0,1 \mathrm{mg} \mathrm{L}^{-1}$ de bencil amino purina (BAP). Los tubos se colocaron en cámara de cultivo a $25^{\circ} \mathrm{C}$ con fotoperíodo de 12 horas e intensidad de 4000 lux.

Cuando las plántulas obtenidas desarrollaron brotes de aproximadamente $1 \mathrm{~cm}$ se repicó a tubos con medio de cultivo MS modificado de la siguiente forma: macro-elementos al $50 \%$ con 0,2 $\mathrm{mg} \mathrm{L}^{-1}$ de ácido naftalen acético (ANA). Los mismos fueron colocados bajo un régimen de iluminación y temperatura similar al de la etapa anterior.

Se comparó la proporción de óvulos germinados respecto al total de óvulos 
sembrados y la cantidad de plántulas obtenidas respecto de los óvulos germinados utilizando la prueba de diferencia de proporciones basadas en la distribución exacta del estadístico de Fisher, según corresponde con el paquete estadístico Infostat (2008). Las pruebas estadísticas que mostraron valor $p<0,05$ fueron consideradas como estadísticamente significativas.

\section{RESULTADOS}

El número de óvulos sembrados en las distintas fechas fue variable en función de la cantidad de óvulos contenidos dentro de los ovarios en los distintos cruzamientos (Tabla 1).

Los óvulos rescatados y sembrados mostraron diferentes comportamientos en su cultivo in vitro. La Tabla 1 muestra el número de óvulos germinados en función del total de óvulos sembrados. A partir de 58 DPP se observó germinación en el cruzamiento $N$. ericoides $\times N$. scoparia (Fig. 1A), mientras que en las combinaciones donde $N$. linariaefolia fue utilizada como padre la germinación comenzaron a los 80 DPP (Fig. 1B, Fig. 2A, Fig. 2B). Entre los óvulos germinados de las dos primeras fechas no se observa una diferencia significativa, al igual que no hay diferencia con el testigo. El dato relevante es la contaminación sufrida en la tercer fecha en las combinaciones incompatibles, que fue de un $100 \%$ (el dato de contaminaciones de las fechas anteriores no se presenta en el trabajo porque no fue relevante).

A partir de los 85 DPP se observó el desarrollo del ápice vegetativo en el cruzamiento $N$. ericoides $\times N$. scoparia, a los 95 DPP en las combinaciones de N. ericoides $\times$ 'Estrella INTA-JICA' y N. ericoides $\times$ 'Cielo INTA' y a los 158 DPP en $N$. ericoides $\times$ 'Luna INTA-JICA'. Como resultados del trabajo fueron obtenidos 10 híbridos interespecíficos provenientes de las combinaciones incompatibles (Tabla 2), habiendo logrado un porcentaje de éxito del $50 \%$ para los cruzamientos $N$. ericoide $\times$ 'Estrella INTA-JICA' (Fig. 3D), 57\% y 66\% para las combinaciones $N$. ericoide $\times$ 'Luna INTAJICA' (Fig. 3A) y N. ericoide $\times$ 'Cielo INTA' (Fig. $3 \mathrm{C})$, respectivamente, sin haber diferencias significativas con el testigo en ninguna de los casos Fig.3B)

\section{DISCUSIÓN}

Se puede concluir que la técnica de rescate embrionario a partir del cultivo de óvulos de Nierembergia permitió obtener exitosamente cruzamientos efectivos entre especies incompatibles. A partir de la técnica aplicada se obtuvieron nuevos genotipos sobre los que se debe

Tabla 1. Número de óvulos extraídos de 10 ovarios y sembrados in vitro en cada fecha/ Cantidad de óvulos germinados en relación a los sembrados.

Table 1. Number of ovules extracted from 10 ovaries and cultured in vitro on each date/ Number of germinated ovules compared to the number of cultivated ovules.

\begin{tabular}{lcc}
\hline & \multicolumn{2}{c}{ Fecha de siembra in vitro } \\
\cline { 2 - 3 } Cruzamiento & $\mathbf{0 3 / 1 0 / 2 0 1 7}$ & $\mathbf{0 3 / 1 1 / 2 0 1 7}$ \\
\hline N. ericoide $\times$ N. scoparia & $323 / 2 \mathrm{a}$ & $398 / 3 \mathrm{a}$ \\
N. ericoide $\times$ N. 'Estrella' & $125 / 3 \mathrm{a}$ & $202 / 1 \mathrm{a}$ \\
N. ericoide $\times$ N. 'Luna' & $378 / 4 \mathrm{a}$ & $259 / 3 \mathrm{a}$ \\
N. ericoide $\times$ N. 'Cielo' & $428 / 4 \mathrm{a}$ & $181 / 2 \mathrm{a}$ \\
\hline
\end{tabular}

Letras diferentes indican diferencias significativas según análisis de proporciones por el estadístico Fisher $(p<0,05)$.

Tabla 2. Cantidad de plantas enraizadas y con desarrollo de brotes en relación a las germinadas. Table 2. Number of rooted plants and with development of shoots compared to the number of germinated ovules.

\begin{tabular}{lccc}
\hline & \multicolumn{3}{c}{ Fecha de siembra in vitro } \\
\cline { 2 - 4 } Cruzamiento & $\mathbf{0 3 / 1 0 / 2 0 1 7}$ & $\mathbf{0 3 / 1 1 / 2 0 1 7}$ & $\mathbf{1 3 / 1 2 / 2 0 1 7}$ \\
\hline N. ericoide $\times$ N. scoparia & $1 / 2 \mathrm{a}$ & $3 / 3 \mathrm{a}$ & $1 / 1$ \\
N. ericoide $\times$ 'Estrella INTA-JICA' & $1 / 3 \mathrm{a}$ & $1 / 1 \mathrm{a}$ & $\mathrm{Sd}$ \\
N. ericoide $\times$ 'Luna' INTA-JICA & $2 / 4 \mathrm{a}$ & $2 / 3 \mathrm{a}$ & $\mathrm{Sd}$ \\
N. ericoide $\times$ 'Cielo INTA' & $2 / 4 \mathrm{a}$ & $2 / 2 \mathrm{a}$ & $\mathrm{Sd}$ \\
\hline
\end{tabular}

Letras diferentes indican diferencias significativas según análisis de proporciones por el estadístico Fisher ( $p<0,05)$. 

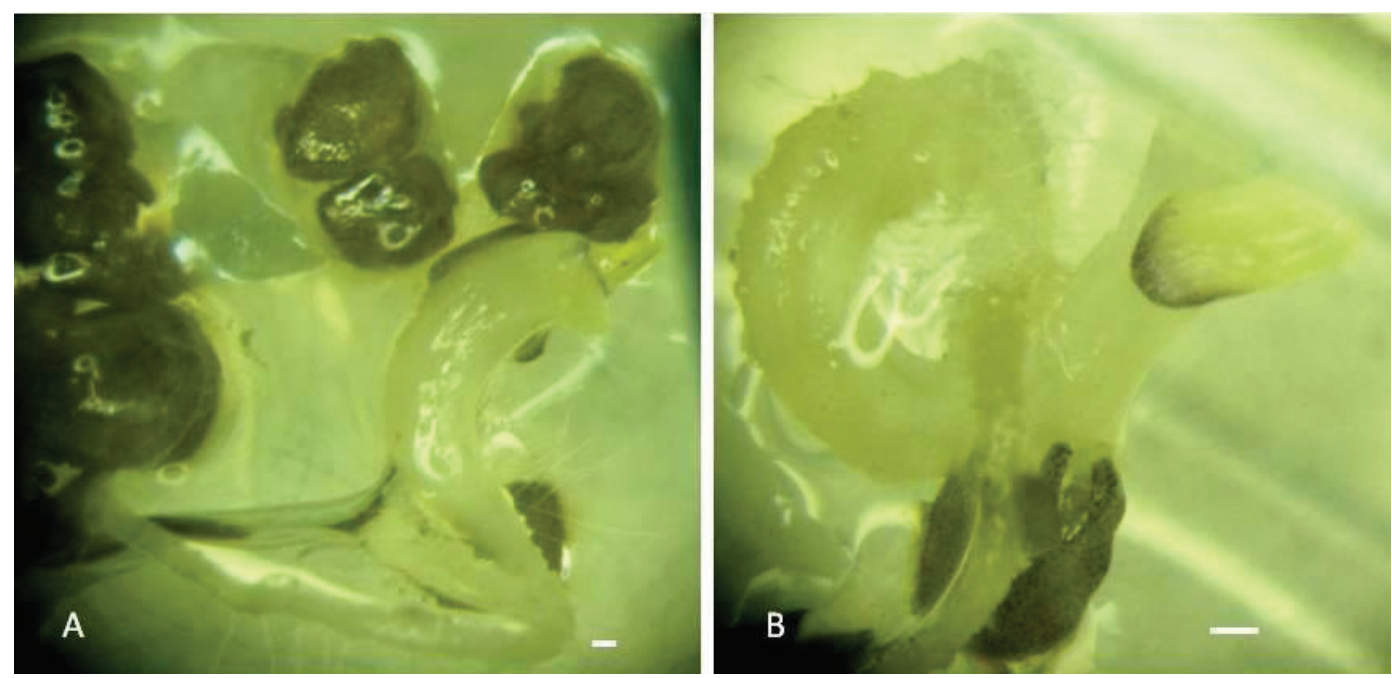

Fig. 1. Germinación de embriones provenientes de cruzamientos interespecíficos entre N. ericoides y $N$. linariaefolia, rescatados a los 7 días post-polinización y cultivados in vitro. A) N. ericoide $\times$ N. scoparia (control); B) N. ericoides $\times$ Cielo INTA.

Aumento: barra $=1 \mathrm{~mL}$

Fig. 1. Germination of embryos from interspecific crosses between N. ericoides and N. linariaefolia, rescued at 7 days post-pollination and cultured in vitro. A) N. ericoide $\times N$. scoparia (control); B) $N$. ericoides $\times$ Cielo INTA.

Increase: bar $=1 \mathrm{~mL}$
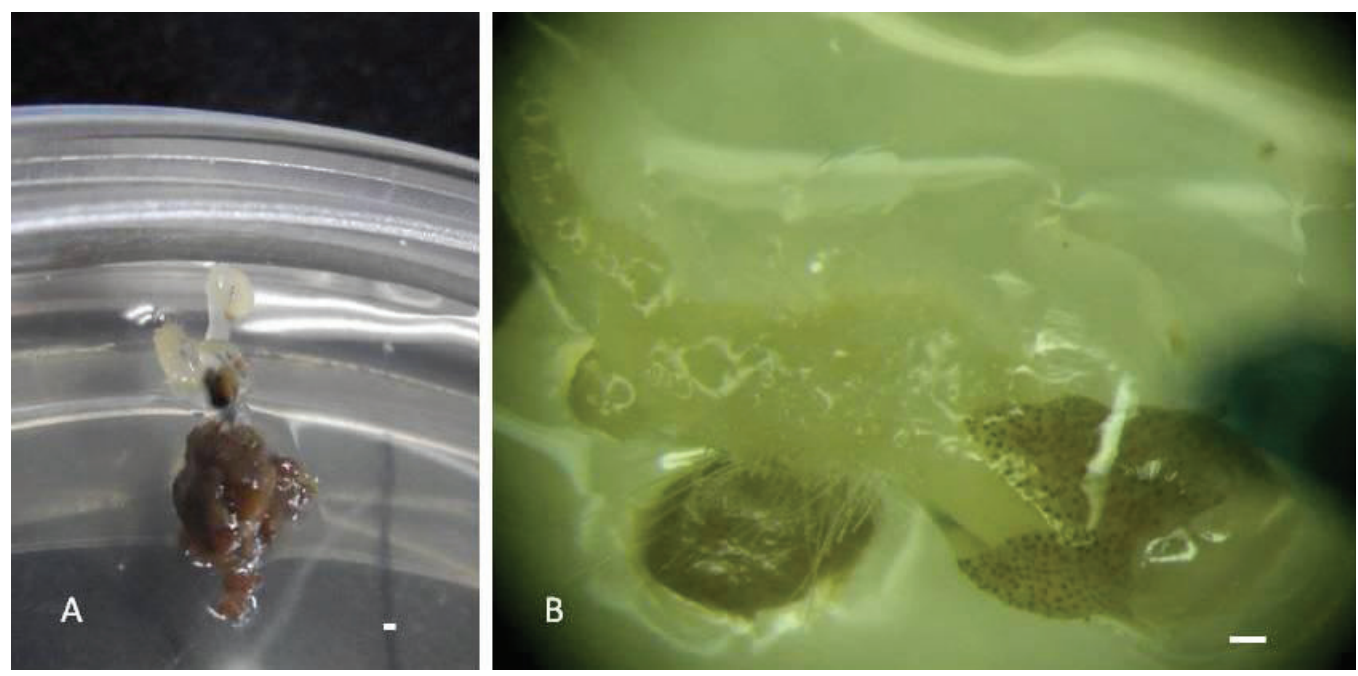

Fig. 2. Germinación de embriones provenientes de cruzamientos interespecíficos entre N. ericoides y $N$. linariaefolia, rescatados a los 7 días post- polinización y cultivados in vitro. A) N. ericoides $\times$ Estrella INTA JICA; B) N. ericoide $\times$ Luna INTA-JICA.

Aumento: barra $=1 \mathrm{~mL}$

Fig. 2. Germination of embryos from interspecific crosses between N. ericoides and N. linariaefolia, rescued at 7 days post-pollination and cultured in vitro. A) N. ericoides $\times$ Estrella INTA JICA; B) N. ericoide $\times$ Luna INTA-JICA.

Increase: bar $=1 \mathrm{~mL}$ 

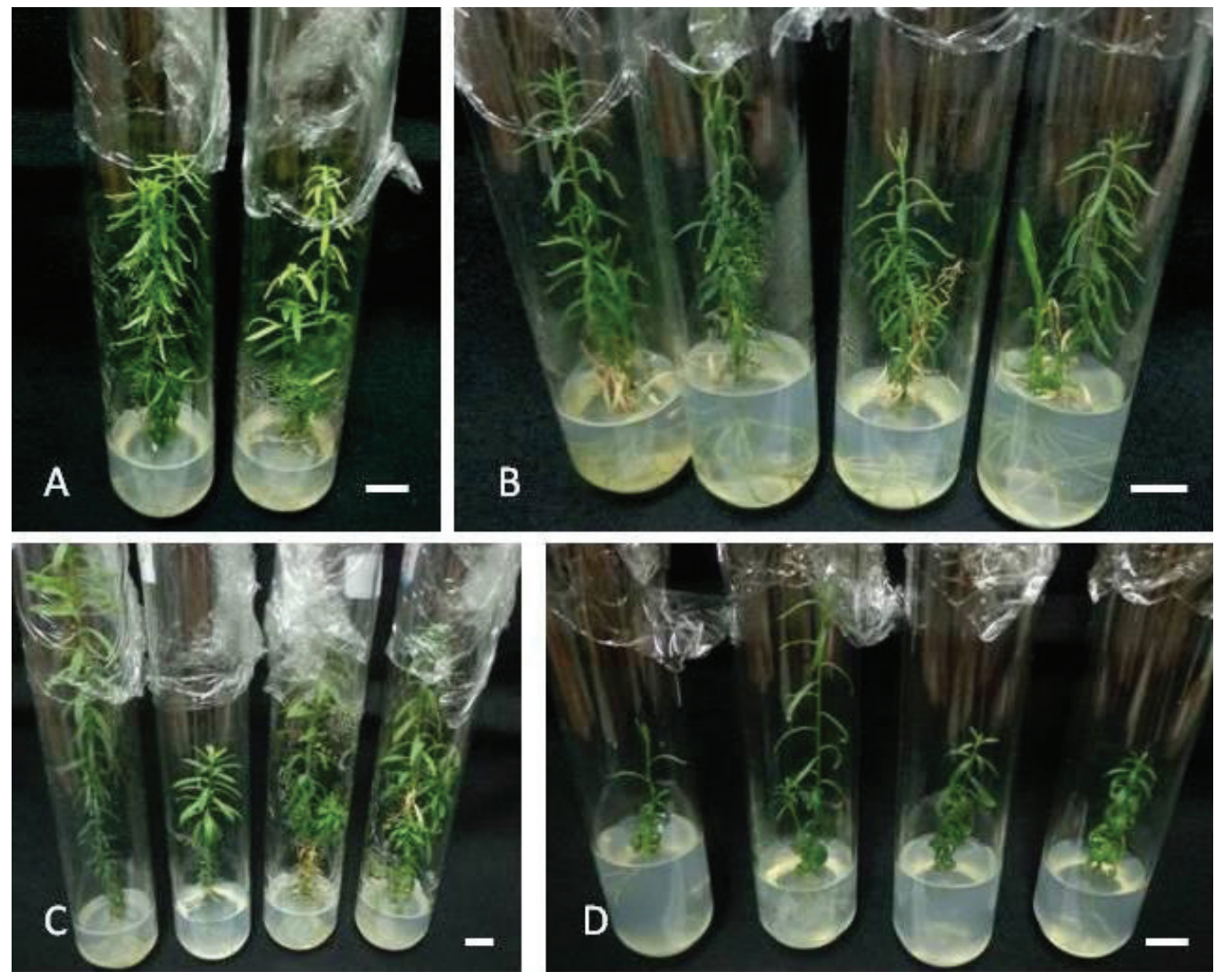

Fig. 3. Híbridos de $N$. ericoides $x$ N. linariaefolia obtenidos por rescate embrionario. A) $N$. ericoide $\mathrm{x}$ Luna INTA-JICA; B) N. ericoide $\times$ N. scoparia (control); C) $N$. ericoide $\times$ Cielo INTA; D) $N$. ericoide $\times$ Estrella INTA-JICA.

Aumento: barra $=1 \mathrm{~cm}$

Fig. 3. HybridsofN.ericoides $\times$ N.linariaefolia obtainedbyembryorescue.A)N.ericoide $\times$ LunaINTA-JICA; B) N.ericoide $\times N$.scoparia (control);C) N.ericoide $\times$ CieloINTA;D) N.ericoide $\times$ EstrellaINTA-JICA. Increase: bar $=1 \mathrm{~cm}$

evaluar la presencia de características deseables en sus fenotipos como para ser utilizados como plantas ornamentales. De estar presentes dichas características de interés en el nuevo híbrido puede propagarse asexualmente como se realiza con gran parte de las plantas ornamentales.

Por otro lado, la obtención de plántulas a partir de cruzamientos incompatibles entre $N$. ericoide y las tres variedades comerciales de $N$. linariaefolia, robustecen los resultados obtenidos en estudios previos de embriología, donde ocurre fecundación seguida de la acción de una fuerte barrera post-cigótica (Soto, 2007). Estos estudios muestran una degeneración del endosperma previa a la del endotelio, iniciando el proceso con una interrupción del desarrollo del endosperma a los siete días posteriores a la polinización, seguida por divisiones anticlinales de las células endoteliales, de una manera no controlada.
Al respecto cabe señalar que estudios realizados en Solanum americanum Mill, sobre los genes SaPIN2a y SaPIN2b, evidencian que el funcionamiento normal del endotelio $\mathrm{y}$ el correcto desarrollo del endosperma y el embrión son procesos interdependientes, regulados por vías comunes (Sin et al., 2006). La interrupción del desarrollo del endosperma podría ser ocasionada por un desbalance en la relación genómica del mismo (Camadro, 2011; Yermishin et al., 2017). Desbalances de este tipo son descriptos por Masuelli y Camadro (1997) en cruzamientos interespecíficos de especies salvajes del género Solanum, donde el desbalance del número endospérmico juega un rol principal en la interrupción del desarrollo del endosperma seguido por una hiperplasia en el endotelio. Al respecto, la relación genómica materna:paterna 2:1 en el endosperma ha sido considerada una 
condición necesaria para el éxito del desarrollo del endosperma tanto en cruzamientos intraespecíficos como interespecíficos (Depetris, 2018).

Teniendo en cuenta estudios cromosómicos en el género Nierembergia, donde se reporta que $N$. ericoides tiene $2 n=2 x=18$ y N. linariaefolia con $2 \mathrm{n}=2 \mathrm{x}=16$ (Acosta et al., 2006), la interrupción del crecimiento del embrión se debería al cese del desarrollo del endosperma debido al desbalance del número endospérmico, provocando la falta de nutrición del embrión y el posterior aborto como consecuencia.

En función de esto, la variación morfológica de los óvulos, el aumento de tamaño continuando en algunos casos con el desarrollo de plántulas durante el cultivo in vitro, estaría dado por la nutrición del embrión a partir del medio de cultivo utilizado para el rescate embrionario. De forma semejante, Honda y Tsutsui (2003) lograron el desarrollo de híbridos incompatibles de Delphinium mediante cultivo in vitro, obteniendo resultados similares con relación al número de plántulas obtenidas en este trabajo. Otros resultados semejantes fueron encontrados en cruzamientos interespecíficos de Lilium y Vitis, donde los óvulos aumentaron de tamaño, tomaron una coloración amarronada, obteniendo un porcentaje muy bajo de germinación (Fernández et al., 1996; Hanfeng, 2001).

Si bien la realización del rescate embrionario a los siete días posterior a la polinización permitió obtener resultados exitosos en la combinación deseada, el porcentaje de plántulas en función de óvulos sembrados fue baja. Este resultado puede estar relacionado con el momento del rescate, pudiendo ser este estadio embrionario muy temprano para permitir la evolución del embrión en forma normal. Esta hipótesis surge del resultado obtenido en los testigos, donde si bien el porcentaje de fecundación es alto también se obtuvo un bajo porcentaje de plántulas. Otro aspecto que puede estar influyendo en el éxito del rescate es el medio de cultivo de la primera etapa, teniendo en cuenta que los repiques posteriores a la germinación no tuvieron pérdidas.

Por otro lado, en aquellos casos en que los óvulos no produjeron cambios en su tamaño y morfología, puede deberse a que el porcentaje de fecundación en estas combinaciones sea bajo por presentarse mayor influencia de barreras precigóticas que post-cigóticas. Procesos similares fueron detectados por Cheung et al. (2000) en trabajos con Nicotiana tabacum donde la falta de interacción entre los estilos y los tubos polínicos llevan a la detención del crecimiento de los mismos, sin llegar a producir fecundación. Estudios previos en las relaciones pre-cigóticas de
Nierembergia confirman que el número de tubos polínicos que llegan al ovario en cruzamientos incompatibles son muy bajos (Milicia, 2015).

Con respecto al alto porcentaje de contaminación encontrado en la última fecha, donde observamos una contaminación del 100\% en las combinaciones incompatibles, podemos inferir que puede estar vinculado al exceso de temperaturas y humedad en el invernáculo que produce un ambiente con condiciones sanitarias desfavorables.

\section{CONCLUSIONES}

Se puede concluir que durante la hibridación entre ambas especies se presentan barreras de incompatibilidad pre-cigóticas y post-cigóticas, pudiendo estas últimas ser superadas por técnicas de rescate embrionario.

\section{LITERATURA CITADA}

Acosta, M.C., A. del V. Ordoñez, A.A. Coccuci, and E.A Moscone. 2006. Chromosome reports in South American Nicotianeae (Solanaceae), with particular reference to Nierembergia. Ann. Missouri Garden 93:634-346.

Birchler, J. A. 2014. Interploidy hybridization barrier of endosperm as a dosage interaction. Front. Plant Sci. 5:281.

Camadro, E.L. 2011. Hibridación y flujo génico en especies silvestres de papa de la Argentina. Journal of Basic \& Applied Genetics. Disponible en http:// www.scielo.org.ar/scielo.php?script $=\mathrm{sci}_{-}$ arttext\&pid=S1852-62332011000100002 \&lng=es\&tlng=es. (Consulta 10 de marzo de 2018).

Chen Y.M., and M. Mii. 2012. Interspecific hybridization of Begonia semperflorens (section Begonia) with B. pearcei (section Eupetalum) for introducing yellow flower color. Plant Biotechnol 29(1):77-85.

Cheng X., S. Chen, F. Chen, W. Fang, Y. Deng, and L. She. 2010. Interspecific hybrids between Dendranthema morifolium(Ramat.). Euphytica. Volume 172:(1)101-108. doi.org/10.1007/ s10681-009-0056-8.

Cheung, A.Y., H.M. Wu, V. Di Stilio, R. Glaven, C. Chen, E. Wong, et al. 2000. Pollen-Pistil Interactions in Nicotiana tabacum. Ann. Botany 85:29-37.

De L.C. 2017. Improvement of ornamental plants. A review. International Journal of Horticulture 7(22):180-204. doi:10.5376/ ijh.2017.07.0022. 
Debbarama, C., V.K. Khanna, W. Tyagi, M. Rai, and N.T. Meetei. 2013. Wide hybridization and embryo-rescue for crop improvement in Capsicum. Agrotechnology S11. doi:10.4172/2168-9881.S11-003.

Depetris M.B., C. Acuña, F. Pozzi, C. Quarin, and S. Felitti. 2018. Identification of genes related to endosperm balance number insensitivity in Paspaslum notatum. Crop Sci. 58(2):813-822. doi:10.2135/cropsci2017.04.0260.

Fernandez, A.M., Nakazaki T., and T. Tanisaka. 1996. Development of diploid and triploid interspecific hybrids between Lilium longiflorum and L. concolor by ovary slice culture. Plant Breeding 115:167-171.

Gaiero, P., C. Mazzella, F. Vilaró, P. Speranza, and H. de Jong. 2017. Pairing analysis and in situ hybridisation reveal autopolyploidlike behaviour in Solanum commersonii $\times S$. tuberosum (potato) interspecific hybrids. Euphytica 213:137. doi.org/10.1007/s10681017-1922-4.

Hanfeng, D., and Q. Guimei. 2001. Ovules culture and plant formation of hybrid progeny of seedless grape. Journal of Agriculture in the Tropics and Subtropics 102:147-152.

Honda, K., H. Watanabe, and K. Tsutsui. 2003. Use of ovule culture to cross between Delphinium species of different ploidy. Euphytica 129:275. doi.org/10.1023/A:1022206731894.

Horn, V. 2002. Breeding methods and breeding research. p. 47-83. In Vainstein, A. (ed.). Breeding for Ornamental Plant: Classical and Molecular Approach. Springer, Dordrecht, Netherlands.

Kato, J., and M. Mii. 2012. Production of interspecific hybrids in ornamental plants. In: Loyola-Vargas V., Ochoa-Alejo N. (eds.) Plant Cell Culture Protocols. Methods in Molecular Biology (Methods and Protocols). Vol 877. Humana Press, Totowa, New Jersey, USA.

Kuligowska, K., H. Lütken, B. Christensen, I. Skovgaard, M. Linde, T. Winkelmann, et al. 2015. Evaluation of reproductive barriers contributes to the development of novel interspecific hybrids in the Kalanchoë genus. BMC Plant Biology15:15. doi 10.1186/s12870014-0394-0.

Liao, J., J. Dai, S. Yang, X. Zhou, L. Ren, Z. Chen, et al.. 2017. Interspecific cross-hybrids of Nicotiana tabacum L. cv. (gla.) S 'K326' with Nicotiana alata. Plant Breeding 136:427-435. doi:10.1111/pbr.12474.
Masuelli, R.W., and E.L. Camadro. 1997. Crossability relationships among wild potato species with different ploidies and endosperm balance numbers (EBN). Euphytica 94:227-235.

Milicia, V.J., M. A. Coviella, G. Facciuto, y M.S. Soto. 2015. Relación tubo polínico/pistilo en cruzamientos interespecíficos en el género Nierembergia (Solanaceae). Chilean J. Agric. Anim. Sci., ex Agro-Ciencia 31(1):53-60.

Pino Pérez, L.A. 2012. Esterilidad masculina citoplomástica en tabaco. Cuba tabaco 13(2):68-71.

Rhee H.K., and S. Kim. 2008. Interspecific hybridization and polyploidization in lily breeding. Acta Hortic. 766:441-446.doi: 10.17660/ActaHortic.2008.766.58.

Resolución 477-E/2017. Instituto Nacional de la Semilla. Disponible en http://www.loa. org.ar/legNormaDetalle.aspx?id=30197. (Consulta 3 de marzo de 2018).

Shivanna, K.R. 2005. Barriers to hybridization. p. 261-272. In Shivanna, K.R. (ed.). Pollen biotechnology for crop production and improvement. Univ. Press, Cambridge, England.

Sin, F.S., E. C. Yeung, and M.L.Chye. 2006. Down regulation of Solanum americanum genes encoding proteinase inhibitor II causes defective seed development. Plant J. 45:5870.

Soto, M.S. 2007. Estudios de las relaciones interespecíficas en el género Nierembergia, como herramientas del mejoramiento. 205 p. Tesis Doctoral. Facultad de Ciencias Exactas y Naturales, Universidad de Buenos Aires, Argentina.

Soto M.S., y A. Coviella. 2013. Manual de cultivo de variedades INTA de Nierembergia para productores. Disponible en https://inta. gob.ar/documentos/manual-de-cultivode-variedades-inta-de-nierembergia-paraproductores.(Consulta 5 de marzo de 2018).

Thompson, J.D., and R. Lumaret. 1992. The evolutionary dynamics of polyploidy plants: origins, establishment and persistence. Trends Ecol. Evol. 7:302-307.

Van Tuyl, J.M., and M. J. De Jeu. 2005. Methods for ovorcoming interespecific crossing barriers. p. 273-292. In Shivana, K.R., Sawhney, V.K. (eds.). Pollen biotecnology and crop production and improvement. University Press, Cambridge, England.

Vignoli-Silva, M. e L.A. Mentz. 2006. O gênero Nierembergia Ruiz \& Pav. (Solanaceae) no Rio Grande do Sul, Brasil. Iheringia Sér. Bot. 61:139-155. 
Yermishin A., A.V. Levy, E.V. Voronkova, Y.V. Polyukhovich, and S. Ageeva. 2017. Overcoming unilateral incompatibility in crosses with wild allotetraploid potato species Solanum stoloniferum Schldtl. \& Bouchet. Euphytica 213:249. doi 10.1007/ s10681-017-2041-y. 